\title{
ANTECIPAÇÃO DA ADUBAÇÃO DE SEMEADURA DO MILHO EM DOIS SISTEMAS DE MANEJO DO SOLO ${ }^{(1)}$
}

\author{
Erick Vinicius Bertolini ${ }^{(2)}$, Carlos Antonio Gamero ${ }^{(3)}$, Ariane da \\ Cunha Salata ${ }^{(4)} \&$ Cassio Roberto Piffer ${ }^{(2)}$
}

\begin{abstract}
RESUMO
Cada sistema de manejo do solo é trabalhado de maneira própria, alterando de forma diferenciada suas propriedades químicas, físicas e biológicas, podendo requerer modificações nas recomendações e no manejo da adubação. Com a finalidade de avaliar o desempenho de três cultivares de milho em relação à adubação realizada em pré-semeadura, comparada à adubação na semeadura, em dois sistemas de manejo do solo, foi realizado este estudo. $O$ experimento foi conduzido na Faculdade de Ciências Agronômicas da UNESP, campus de BotucatuSP, no período de novembro de 2003 a maio de 2004, em Nitossolo Vermelho distroférrico. $\mathrm{O}$ delineamento experimental utilizado foi o de blocos ao acaso com parcelas subsubdivididas e quatro repetições. As parcelas foram constituídas pelos sistemas de manejo do solo (plantio direto e preparo reduzido com escarificação); as subparcelas, pelas épocas de adubação (adubação de pré-semeadura na superfície do solo, realizada 22 dias antes da semeadura do milho, e adubação feita junto com a semeadura do milho, sendo os fertilizantes incorporados ao solo); e as subsubparcelas, pelos cultivares de milho (DKB 333B, CO 32 e AL Bandeirante), totalizando 12 tratamentos. Os dados de produtividade, componentes de produção e teores de $\mathrm{N}, \mathrm{P}$ e K no tecido foliar foram submetidos à análise de variância è̀ análises multivariadas de agrupamentos e de componentes principais. Os sistemas de manejo do solo não influíram no desempenho da cultura do milho, tampouco as épocas de adubação. As diferenças observadas nos componentes de produção e no desempenho da cultura do milho foram decorrentes, principalmente, da divergência genética dos cultivares de milho.
\end{abstract}

Termos de indexação: Zea mays, adubação de pré-semeadura, plantio direto, escarificação.

\footnotetext{
(1) Parte da Dissertação de Mestrado do primeiro autor apresentada à Faculdade de Ciências Agronômicas, Universidade Estadual Paulista - FCA/UNESP. Projeto financiado pela CAPES. Recebido para publicação em outubro de 2007 e aprovado em setembro de 2008.

${ }^{(2)}$ Doutorando do Programa de Pós-Graduação em Agronomia (Energia na Agricultura) - FCA/UNESP. Campus de Botucatu, Caixa Postal 237, CEP 18610-307 Botucatu (SP). Bolsista CNPq. E-mail: evbertolini@fca.unesp.br; cassiopiffer@fca.unesp.br

(3) Professor Titular do Departamento de Engenharia Rural, FCA/UNESP. E-mail: gamero@fca.unesp.br

${ }^{(4)}$ Doutoranda do Programa de Pós-Graduação em Agronomia (Horticultura), FCA/UNESP. E-mail: acsalata@fca.unesp.br
} 


\title{
SUMMARY: ANTICIPATION OF STARTER FERTILIZER APPLICATION FOR CORN UNDER TWO SOIL TILLAGE SYSTEMS
}

\begin{abstract}
Each soil tillage system has its proper characteristics, which have distinct effects on the chemical, physical and biological soil properties, and may require adaptations of fertilization recommendations and management. This study was conducted to evaluate the performance of three maize cultivars with fertilizer application before and at sowing in two soil tillage systems. The experiment was carried out at the "Faculdade de Ciências Agronomicas", UNESP, Botucatu-SP campus, from November 2003 to May 2004, in a Dystric Nitosol (FAO). The experimental design was in randomized blocks with split-split plots and four repetitions. The main plots consisted of two soil tillage systems (no-tillage and reduced tillage with chisel plow), the split-plots of fertilizer application time (surface fertilizer application 22 days before maize sowing and fertilizer application incorporated to soil simultaneously to maize sowing) and split-split-plots of maize cultivars (DKB 333B, CO 32 and AL Bandeirante), totalizing 12 treatments. The data of productivity, yield components and $N, P$ and $K$ contents in the leaf tissue were submitted to analysis of variance and multivariate analysis of Grouping and Principal Components. The soil tillage systems did not influence the performance of the maize crop, neither the timing of starter fertilizer application. The differences observed in the yield components and the maize crop performance were mainly due to genetic divergences among the maize cultivars.
\end{abstract}

Index terms: Zea mays, starter fertilizer, no-tillage, chisel plow.

\section{INTRODUÇÃO}

Cada sistema de manejo do solo altera de forma diferenciada as suas propriedades. O preparo reduzido com escarificação desagrega o solo no sentido ascendente, mantendo parte da cobertura vegetal sobre ele e, por meio das fendas originadas pela ação do escarificador, pode promover a incorporação dos fertilizantes aplicados na superfície em maiores profundidades, quando comparado ao plantio direto. Também, por aumentar a macroporosidade, em relação ao plantio direto, pode facilitar a lixiviação dos nutrientes de maior mobilidade no perfil do solo.

A mínima mobilização do solo no sistema plantio direto promove decomposição mais lenta e gradual do material orgânico, resultando em melhorias das condições físicas, químicas e biológicas no solo, as quais podem repercutir na sua fertilidade e na produtividade das culturas (Moody et al., 1961), levando, assim, à necessidade de recomendação de adubação e calagem diferenciada para este sistema.

Mai et al. (2003) comprovaram que no plantio direto, quando o milho é cultivado em sucessão à aveiapreta (alta relação $\mathrm{C} / \mathrm{N}$ ), os 20 a $30 \mathrm{~kg} \mathrm{ha}^{-1}$ de $\mathrm{N}$ que são recomendados para a cultura por ocasião da semeadura podem ser insuficientes para atender às necessidades das plantas de milho nos estádios iniciais de seu crescimento e desenvolvimento.

Maiores respostas do milho à adubação nitrogenada têm sido observadas com o aumento das doses, pretendendo-se, dessa forma, contornar a carência de
$\mathrm{N}$ na fase inicial de crescimento das culturas, causada pelo efeito da imobilização do N mineral (Silva et al., 2006). Outra opção seria a antecipação da adubação nitrogenada do milho. Algumas pesquisas, realizadas principalmente no Sul do Brasil, têm demonstrado vantagens na aplicação do $\mathrm{N}$ em pré-semeadura do milho. O principal argumento é de que o $\mathrm{N}$ pode ser imobilizado momentaneamente pela matéria orgânica, em especial pelos resíduos com alta relação $\mathrm{C} / \mathrm{N}$, e se tornar disponível para a cultura do milho posteriormente nos estádios de maior demanda, pois os fatores que favorecem a mineralização do $\mathrm{N}$ retido na fração orgânica - alta temperatura e umidade são os mesmos que promovem o crescimento do milho (Cantarella \& Duarte, 2004).

No sistema plantio direto, a aplicação antecipada de fertilizantes que contêm $\mathrm{P}$ e $\mathrm{K}$ pode ser uma alternativa para tornar mais rápida a operação de semeadura de milho (Pöttker \& Wiethölter, 1999). A alternativa de se aplicar o $\mathrm{N}$ em pré-semeadura do milho tem despertado grande interesse porque, apresenta algumas vantagens operacionais, como maior flexibilidade no período de execução da adubação, pelo maior rendimento operacional de máquinas, pela maior facilidade de distribuição a lanço, economia de tempo e de mão-de-obra, menor custo operacional de máquinas e redução no gasto de combustível, lubrificante e reparos (Ceretta, 1998; Coelho et al., 2002).

Entretanto, além do sistema de manejo do solo e da relação $\mathrm{C} / \mathrm{N}$ dos resíduos vegetais, outras variáveis 
condicionam a dinâmica do $\mathrm{N}$, sobretudo a classe de solo e a precipitação pluvial, que pode diferir em função do ano e do local.

Cantarella \& Duarte (2004) mencionam que a antecipação da aplicação do $\mathrm{N}$ pode ser uma prática pouco segura em solos arenosos, devido à sua maior suscetibilidade a perdas por lixiviação. Basso \& Ceretta (2000) mostraram que a aplicação de N em pré-semeadura em solo com textura superficial francoarenosa é uma prática de risco. Já em solo argiloso, Sá (1996) observou na região de Campos Gerais no Paraná, onde há distribuição regular de chuvas durante o inverno, promovendo a formação de uma espessa cobertura de palha que permanece sobre o solo durante o verão, que a antecipação da aplicação do $\mathrm{N}$ não diminuiu a produtividade de milho em relação à aplicação convencional e, em alguns casos, foi até vantajosa.

Em anos com distribuição normal das precipitações pluviais, Basso \& Ceretta (2000), trabalhando em um Argissolo Vermelho distrófico arênico, observaram que a antecipação da adubação nitrogenada promoveu incrementos na produtividade do milho cultivado em sucessão a aveia-preta. Na ocorrência de precipitações pluviais intensas, como as observadas durante o fenômeno "El Niño", do ano agrícola de 1997/98, esses autores observaram que a produtividade de grãos de milho foi inferior com a adubação de pré-semeadura. No entanto, Wolschick et al. (2003), trabalhando em um Argissolo Vermelho-Amarelo distrófico arênico, não observaram diferença na produtividade de grãos das plantas submetidas à aplicação de $\mathrm{N}$ em pré-semeadura e à aplicação parcelada nas mesmas condições pluviais daquele ano agrícola, provavelmente porque utilizaram doses mais elevadas de $\mathrm{N}$ em pré-semeadura e pelo menor intervalo de tempo entre a aplicação de $\mathrm{N}$ e a semeadura, em relação àqueles autores.

Outro fator que pode interferir no aproveitamento da adubação pela cultura do milho é a escolha do cultivar. Moll et al. (1982) observaram em seis híbridos de milho que, com baixas doses de $\mathrm{N}$, a diferença entre eles se deveu à variação na eficiência da utilização do $\mathrm{N}$ acumulado antes da antese; para altas doses de $\mathrm{N}$, os autores relataram que a diferença foi devida à variação na eficiência de sua absorção.

Com base no exposto, estabeleceu-se a hipótese de que a adubação de pré-semeadura da cultura do milho pode promover acréscimo na produtividade de grãos pela maior disponibilidade de $\mathrm{N}$ nos estádios iniciais de crescimento e desenvolvimento e que diferentes cultivares de milho e sistemas de manejo do solo respondem de maneira diferenciada à antecipação da adubação. Assim, o objetivo deste estudo foi avaliar o desempenho de três cultivares de milho mediante adubação em pré-semeadura, comparada à adubação na semeadura, nos sistemas plantio direto e preparo reduzido do solo.

\section{MATERIAL E MÉTODOS}

O experimento foi instalado e conduzido no período de novembro de 2003 a maio de 2004, na Fazenda Experimental Lageado, da Faculdade de Ciências Agronômicas da UNESP, campus de Botucatu, Estado de São Paulo. A localização geográfica está definida pelas coordenadas $22^{\circ} 51$ ' 22 " de latitude sul e $48^{\circ} 26$ ' 08 " de longitude oeste de Greenwich, com altitude média de $770 \mathrm{~m}$, declividade média de $5 \%$ e exposição oeste. A área experimental era cultivada até 1999 com o sistema convencional de preparo do solo, caracterizado por uma aração e duas gradagens leves. A partir do ano de 2000, teve início o sistema plantio direto, com rotação soja e milho no verão e pousio no inverno, para formação de palhada pela vegetação espontânea. No ano de 2003, a vegetação espontânea foi, predominantemente, composta por nabiça (Raphanus raphanistrum L.), com média de $8.109 \mathrm{~kg} \mathrm{ha}^{-1}$ de massa seca e $93 \%$ de cobertura da superfície do solo, sem diferir significativamente entre as parcelas, indicando homogeneidade da área experimental antes da instalação dos tratamentos.

O clima predominante no município de BotucatuSP, segundo classificação de Köppen, é do tipo Cfa, temperado quente (mesotérmico) úmido, temperatura média anual de $20,3^{\circ} \mathrm{C}$, temperatura média do mês mais quente superior a $22{ }^{\circ} \mathrm{C}$ e índice médio pluvial anual de $1.428 \mathrm{~mm}$ (Cunha \& Martins, 2008). O solo da área experimental foi classificado por Carvalho et al. (1983) como Terra Roxa Estruturada Unidade Lageado textura muito argilosa, sendo atualmente denominado Nitossolo Vermelho distroférrico (Embrapa, 1999) (Quadro 1).

O experimento foi constituído por 12 tratamentos, sendo a combinação de dois sistemas de manejo do solo, duas épocas de adubação e três cultivares de milho.

Quadro 1. Principais propriedades químicas do Nitossolo Vermelho distroférrico na camada de 0-20 cm de profundidade, antes da instalação do experimento

\begin{tabular}{cccccccccc}
\hline $\mathbf{p H ~ C a C l}$ & MO & $\mathbf{P}_{\text {resina }}$ & $\mathbf{H}+\mathbf{A l}$ & $\mathbf{K}$ & $\mathbf{C a}$ & $\mathbf{M g}$ & $\mathbf{S B}$ & $\mathbf{C T C}$ & $\mathbf{V}$ \\
\hline & $\mathrm{g} \mathrm{dm}^{-3}$ & $\mathrm{mg} \mathrm{dm}^{-3}$ & & & & $\mathrm{mmol}_{\mathrm{c}} \mathrm{dm}^{-3}$ & & \\
\cline { 5 - 7 } & & 59 & 18 & 4,6 & 62 & 29 & 95,6 & 113,6 & 84 \\
\hline
\end{tabular}


Os sistemas de manejo do solo empregados foram: $\mathrm{P} 1$ - plantio direto e $\mathrm{P} 2$ - preparo reduzido por meio de escarificação profunda do solo. As épocas de adubação da cultura do milho foram: E1 - adubação de pré-semeadura, sendo os fertilizantes distribuídos na superfície do solo em área total sem incorporação, 22 dias antes da semeadura do milho; e E2 - adubação realizada simultaneamente com a operação de semeadura do milho, sendo os fertilizantes distribuídos em linha e incorporados ao solo pela semeadora-adubadora. Os cultivares utilizados foram: C1 - DKB 333B (híbrido simples modificado semiprecoce), C2 - CO 32 (híbrido triplo precoce) e C3-AL Bandeirante (variedade semiprecoce da Secretaria da Agricultura do Estado de São Paulo). Deve-se salientar que os cultivares escolhidos estavam entre os mais produtivos nos ensaios realizados pela Secretaria da Agricultura na região de Botucatu-SP e, em dias de campo, realizados pelas Fazendas de Ensino, Pesquisa e Produção da FCA/UNESP.

O delineamento experimental utilizado foi o de blocos ao acaso com parcelas subsubdivididas e quatro repetições, sendo as parcelas constituídas pelos sistemas de manejo do solo, as subparcelas, pelas épocas de adubação, e as subsubparcelas, pelos cultivares de milho, num total de oito parcelas, 16 subparcelas e 48 subsubparcelas. Cada parcela apresentava $20 \mathrm{~m}$ de comprimento por $22 \mathrm{~m}$ de largura; as subparcelas, $20 \mathrm{~m}$ de comprimento por $11 \mathrm{~m}$ de largura; e as subsubparcelas, $20 \mathrm{~m}$ de comprimento por 3,6 m de largura. Foram deixados carreadores de $10 \mathrm{~m}$ de comprimento entre as parcelas, para estabilização dos conjuntos motomecanizados e também para as manobras.

A escarificação profunda do solo foi realizada no dia 21/11/2003, com equipamento provido de disco de corte de palhada e rolo destorroador na profundidade efetiva entre 25 e $30 \mathrm{~cm}$. A adubação de pré-semeadura das subsubparcelas foi realizada em 24/11/2003 por meio de distribuidor de corretivos e fertilizantes com sistema de distribuição por gravidade através de esteira transportadora acionada pelo rodado, distribuindo os adubos diretamente na superfície do solo. A adubação das demais subsubparcelas foi feita junto com a semeadura do milho no dia 16/12/2003, com uma semeadora-adubadora para plantio direto de quatro linhas espaçadas a $90 \mathrm{~cm}$, distribuição de sementes com discos perfurados horizontais e intercambiáveis, distribuição de adubo com rotores dentados, disco de corte corrugado e mecanismos sulcadores tipo discos duplos para fertilizante e semente. Foi feita distribuição de 5,4 sementes viáveis por metro para cada um dos cultivares.

$\mathrm{O}$ atraso na semeadura ocorreu pelo fato de serem inadequadas as reservas hídricas do solo para o preparo e insuficientes para a emergência e estabelecimento das plântulas em outubro e na primeira quinzena de novembro. Depois de realizada a escarificação e a adubação de pré-semeadura, ocorreram precipitações pluviais que impediram a semeadura do milho até que o solo estivesse com o teor de água adequado para a realização dessa operação.

Nos tratamentos de plantio direto, em que a mobilização foi efetuada apenas na linha de semeadura, praticamente manteve-se a percentagem de cobertura vegetal sobre o solo. No preparo reduzido, parte desse material foi incorporada pela escarificação, diminuindo a cobertura do solo para $47 \%$, aproximadamente.

Para adubação, tanto nos tratamentos de présemeadura como nos tratamentos em que a adubação foi realizada no momento da semeadura do milho, foram aplicados $30 \mathrm{~kg} \mathrm{ha}^{-1} \mathrm{de} \mathrm{N}, 50 \mathrm{~kg} \mathrm{ha}^{-1}$ de $\mathrm{P}_{2} \mathrm{O}_{5} \mathrm{e}$ $50 \mathrm{~kg} \mathrm{ha}^{-1}$ de $\mathrm{K}_{2} \mathrm{O}$. Quanto à adubação de cobertura, foram utilizados $100 \mathrm{~kg} \mathrm{ha}^{-1}$ de $\mathrm{N}$ em uma única aplicação, no estádio de cinco a seis folhas totalmente expandidas. Essas quantidades foram aplicadas com base nas recomendações de adubação e calagem para o Estado de São Paulo (Raij et al., 1996).

Foram avaliadas na cultura do milho as seguintes características agronômicas: populações inicial e final de plantas, determinadas após a estabilização da emergência e no momento da colheita, respectivamente; número de plantas quebradas, determinado contando-se as plantas que estavam quebradas abaixo da primeira espiga; diâmetro do colmo, determinado medindo-se o primeiro internódio a partir da superfície do solo; altura das plantas, obtida medindo-se a distância entre a superfície do solo e a inserção da folha-bandeira na época do florescimento da cultura; altura de inserção da primeira espiga, determinada pela distância entre a superfície do solo e a inserção da primeira espiga; índice de colheita, obtido pela relação entre produtividade de grãos e massa seca das plantas de milho; teores de N, P e K, determinados numa amostra do terço central de 40 folhas da base da espiga coletadas na fase de pendoamento, sendo as análises realizadas pelo laboratório do Departamento de Recursos Naturais, setor de Ciência do Solo, da FCA/UNESP; índice de espiga, determinado pela relação entre número de espigas e número de plantas; comprimento da espiga, diâmetro da espiga, número de fileiras e grãos por espiga, avaliados a partir de uma amostra de 10 espigas coletadas aleatoriamente em cada subsubparcela; produtividade, obtida pela massa de grãos das espigas contidas em $5 \mathrm{~m}$ nas duas linhas centrais de cada subsubparcela com $13 \%$ de água; e, em seguida, foi determinada a massa de mil grãos, ajustada também a $13 \%$ de água.

Os resultados obtidos referentes a produtividade, componentes de produção da cultura do milho e teores de N, P e K no tecido foliar foram submetidos à análise de variância e aos métodos multivariados por meio da análise de agrupamento e de componentes principais, de forma a distinguir os tratamentos semelhantes e qual ou quais variáveis interferiram nessa classificação. 
A análise de componentes principais foi utilizada com a intenção de reduzir o conjunto, inicialmente de 17 características avaliadas na cultura do milho, para duas novas variáveis não correlacionadas entre si, que são os componentes principais indicados como Y1 e Y2. Cada um desses componentes, que em conjunto formam um novo espaço a duas dimensões, é uma combinação linear das variáveis originais, com a capacidade de reter a maior quantidade possível das informações. A análise de componentes principais também permitiu visualizar a capacidade discriminatória de cada característica avaliada no processo de formação dos grupos, o que é indicado pelo coeficiente de correlação.

A aplicação da análise de agrupamento foi precedida por um pré-tratamento dos dados, pois as variáveis são de escalas diferentes. Quando não é feito o pré-tratamento, as variáveis com valores numéricos mais altos serão mais importantes no cálculo do que as variáveis com valores numéricos mais baixos. $\mathrm{O}$ pré-tratamento empregado foi a transformação Z, que alterou as medidas de cada variável de tal modo que o conjunto de dados tivesse média zero e variância 1 . Então, para realização da análise de agrupamentos utilizaram-se os dados transformados, calculando-se as distâncias euclidianas médias entre os tratamentos para o conjunto das 17 variáveis estudadas. Foi utilizado o algoritmo não ponderado UPGMA (Unweighted Pair Group Method with Arithmetic Average) de agrupamento aos pares, usando médias aritméticas, por ser a técnica mais utilizada onde o espaço é conservativo. Os resultados finais desses agrupamentos foram apresentados na forma de um dendrograma.

\section{RESULTADOS E DISCUSSÃO}

Constataram-se diferenças significativas entre os sistemas de manejo do solo para altura de plantas, altura de inserção da primeira espiga e teor de $\mathrm{P}$ e K nas folhas, com os maiores valores observados no preparo reduzido (Quadro 2). O menor teor de P no plantio direto se deve ao pouco tempo de implantação desse sistema. Tokura et al. (2002) verificaram que com o tempo de cultivo sob plantio direto, em uma mesma classe de solo, a participação das formas de $\mathrm{P}$ não-lábeis em relação ao $\mathrm{P}$ total tendeu a diminuir, sendo acompanhada por aumento relativo das formas mais lábeis. $\mathrm{O} \mathrm{K}$, diferentemente do $\mathrm{P}$, dilui-se parcialmente na água e é transportado para camadas mais profundas. Contudo, Rosolem et al. (2006) observaram que a palha de milheto na superfície do solo, com a chuva, aumentou a quantidade de $\mathrm{K}$ nos primeiros $2 \mathrm{~cm}$ de profundidade, mas diminuiu a lixiviação do nutriente na coluna do solo em relação ao tratamento com ausência de palha na superfície devido à liberação de ácidos orgânicos da palha, que podem ter atuado como ligantes, proporcionando maior retenção do K nas camadas mais superficiais do solo.

A produtividade não diferiu entre os sistemas de manejo do solo, possivelmente devido ao fato de o plantio direto ter sido instalado há apenas três anos na área experimental. Dick et al. (1991) verificaram que as produções da cultura do milho foram menores no plantio direto nos primeiros anos de cultivo, aumentando seu potencial a partir do terceiro ano de implantação do sistema.

Quadro 2. Valores do teste F obtidos nas análises de variância das características avaliadas em função dos sistemas de manejo do solo (P), das épocas de adubação (E) e dos cultivares de milho (C)

\begin{tabular}{|c|c|c|c|c|c|c|c|}
\hline Fonte de variação & $\mathbf{P}$ & $\mathbf{E}$ & C & PxE & PxC & ExC & PxExC \\
\hline População inicial & 0,27 & 0,03 & 11,79 * & 0,48 & 0,94 & 1,73 & 0,48 \\
\hline População final & 0,00 & 0,15 & 19,58 * & 1,74 & 1,04 & 2,75 & 1,61 \\
\hline $\mathrm{N}^{\circ}$. de plantas quebradas & 3,82 & 0,24 & 4,07 * & 0,24 & 1,36 & 0,46 & 0,01 \\
\hline Diâmetro do colmo & 0,02 & 0,24 & 34,28 * & 4,34 * & 2,53 & 0,67 & 0,91 \\
\hline Altura de plantas & 10,68 * & 4,02 & $22,88^{*}$ & 1,37 & 0,59 & 0,28 & 1,40 \\
\hline Altura de inserção da primeira espiga & 9,85 * & 5,45 * & 19,34 * & 0,77 & 0,24 & 0,68 & 1,08 \\
\hline Índice de colheita & 1,02 & 1,44 & $3,47^{*}$ & 4,73 * & 1,04 & 0,84 & 1,19 \\
\hline Teor de nitrogênio nas folhas & 2,68 & 3,37 & 1,45 & 0,12 & 0,83 & 0,60 & 0,98 \\
\hline Teor de fósforo nas folhas & 19,07 * & 0,67 & 20,42 * & 2,51 & 0,79 & 0,65 & 0,77 \\
\hline Teor de potássio nas folhas & $7,99 *$ & 0,80 & 13,36 * & 0,02 & 1,90 & 1,51 & 0,11 \\
\hline Índice de espiga & 0,34 & 2,79 & 8,16 * & 0,70 & 0,89 & 0,64 & 1,37 \\
\hline Comprimento da espiga & 0,01 & 1,55 & $35,37^{*}$ & 3,11 & 0,12 & 0,37 & 1,58 \\
\hline Diâmetro da espiga & 0,54 & 0,73 & 0,52 & 1,96 & 1,94 & 1,06 & 1,04 \\
\hline $\mathrm{N}^{\circ}$. de fileiras de grãos por espiga & 0,02 & 2,02 & 1,57 & 0,77 & 1,31 & 0,44 & 1,29 \\
\hline $\mathrm{N}^{\circ}$. de grãos por espiga & 0,00 & 0,46 & 0,84 & 0,08 & 0,43 & 1,63 & 1,49 \\
\hline Massa de mil grãos & 1,11 & 0,04 & 5,72 * & 0,14 & 1,27 & 0,98 & 0,94 \\
\hline Produtividade & 0,12 & 0,60 & 21,83 * & 0,08 & 1,32 & 2,54 & 2,21 \\
\hline
\end{tabular}

* indicação de diferença significativa obtida na análise de variância. 
Ocorreram diferenças significativas entre as épocas de adubação apenas para a altura de inserção da primeira espiga e entre os cultivares para população inicial, população final, número de plantas quebradas, diâmetro do colmo, altura de plantas, altura de inserção da primeira espiga, índice de colheita, teor de $\mathrm{P}$ e K nas folhas, índice de espiga, massa de mil grãos e produtividade. Com relação às interações, verificou-se diferença significativa apenas para diâmetro do colmo e índice de colheita na interação entre manejo do solo e época de adubação.

Portanto, de acordo com a análise de variância, pode-se observar que a maioria das diferenças encontradas é decorrente, principalmente, dos cultivares de milho utilizados neste estudo. Essa diferença entre os cultivares já era esperada, devido à divergência genética entre o híbrido simples modificado DKB 333B, o híbrido triplo CO 32 e a variedade AL Bandeirante. Os híbridos simples são potencialmente mais produtivos do que os outros tipos de materiais, mostrando maior uniformidade de plantas e espigas. Os híbridos triplos são também bastante uniformes e seu potencial produtivo é intermediário entre os híbridos simples e duplos. As variedades possuem base genética ampla, com alguns caracteres agronômicos em comum que as diferenciam de outros materiais, o que diminui a uniformidade de plantas e espiga; contudo, apesar de terem menor potencial produtivo em relação aos híbridos, possuem maior grau de adaptabilidade a diferentes condições e baixo custo de aquisição de sementes.

Os maiores valores para o diâmetro do colmo foram observados nos tratamentos P1E1C1, P1E2C1, P2E2C1 e P2E1C1, o que pode ser justificado pela uniformidade inerente ao híbrido simples em questão, pois, mesmo com variações na população entre os tratamentos a que foi submetido, ele sempre obteve valores para diâmetros entre 23 e 24 mm (Quadro 3). $\mathrm{O}$ menor valor de diâmetro foi observado no tratamento $\mathrm{P} 2 \mathrm{E} 1 \mathrm{C} 2$, podendo isso estar relacionado com as maiores populações inicial e final observadas nesse tratamento.

As características altura de plantas e de espigas são altamente correlacionadas, e neste estudo pode-se verificar que, quanto maior a altura da planta, maior foi a altura de inserção da primeira espiga. $\mathrm{O}$ tratamento P1E1C2 apresentou as menores alturas de plantas e de inserção da primeira espiga, ao passo que o tratamento $\mathrm{P} 2 \mathrm{E} 2 \mathrm{C} 3$ proporcionou as maiores alturas. A altura extrema de planta e a alta proporção entre altura de plantas e altura de espigas podem fazer com que o cultivar apresente maior suscetibilidade ao acamamento ou ao quebramento, não sendo indicado para cultivo em locais com grande intensidade de ventos e com solos férteis, o que faz com que a planta cresça em demasia (Miranda et al., 2003). Assim, concordando com essa afirmação, em razão de suas maiores alturas de plantas e de inserção da espiga, o tratamento $\mathrm{P} 2 \mathrm{E} 2 \mathrm{C} 3$ apresentou maior número de plantas quebradas. Já para o P2E1C2, o número de plantas quebradas se deve às maiores populações inicial e final observadas nesse tratamento, concordando com os resultados obtidos por Pereira Filho et al. (2002) e Gross et al. (2006) quando avaliaram o aumento da densidade populacional na cultura do milho, e também ao menor diâmetro do colmo verificado nesse tratamento.

O índice de colheita (IC) é a razão entre o produto econômico e a biomassa da parte aérea, estimando o fracionamento de matéria seca entre os grãos e a parte

Quadro 3. Valores médios de população inicial (PI), população final (PF), número de plantas quebradas (PQ), diâmetro do colmo (DC), altura de plantas (AP), altura de inserção da primeira espiga (AE), índice de colheita (IC), teor de nitrogênio, fósforo e potássio nas folhas

\begin{tabular}{|c|c|c|c|c|c|c|c|c|c|c|}
\hline Tratamento & PI & PF & $\mathbf{P Q}$ & DC & AP & $\mathbf{A E}$ & IC & $\mathbf{N}$ & $\mathbf{P}$ & $\mathbf{K}$ \\
\hline & & plantas ha ${ }^{-1}$ & - & $\mathrm{mm}$ & 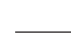 & ـ & & 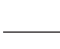 & $\mathrm{g} \mathrm{kg}^{-1}$ & - \\
\hline P1E1C1 & 67.941 & 66.765 & 556 & 23,83 & 2,17 & 1,21 & 1,02 & 28 & 3,0 & 21 \\
\hline $\mathrm{P} 1 \mathrm{E} 1 \mathrm{C} 2$ & 64.706 & 64.118 & 1.667 & 21,76 & 1,94 & 1,04 & 1,13 & 27 & 3,6 & 23 \\
\hline P1E1C3 & 60.000 & 55.294 & 278 & 21,81 & 2,14 & 1,21 & 0,97 & 28 & 3,1 & 19 \\
\hline P1E2C1 & 64.118 & 61.176 & 833 & 23,42 & 2,29 & 1,29 & 1,08 & 32 & 2,9 & 20 \\
\hline P1E2C2 & 68.529 & 67.941 & 1.667 & 20,11 & 2,03 & 1,12 & 1,38 & 26 & 3,3 & 22 \\
\hline P1E2C3 & 61.765 & 60.294 & 1.111 & 21,74 & 2,19 & 1,26 & 1,24 & 29 & 2,9 & 19 \\
\hline P2E1C1 & 65.882 & 63.235 & 833 & 23,12 & 2,30 & 1,32 & 0,97 & 26 & 3,3 & 24 \\
\hline P2E1C2 & 69.118 & 68.235 & 2.500 & 20,09 & 2,10 & 1,14 & 1,07 & 26 & 4,0 & 24 \\
\hline P2E1C3 & 61.765 & 59.412 & 1.944 & 22,34 & 2,20 & 1,26 & 1,28 & 26 & 3,1 & 19 \\
\hline P2E2C1 & 63.529 & 60.294 & 556 & 23,37 & 2,26 & 1,28 & 0,94 & 27 & 3,2 & 24 \\
\hline $\mathrm{P} 2 \mathrm{E} 2 \mathrm{C} 2$ & 69.118 & 67.353 & 2.222 & 20,64 & 2,11 & 1,20 & 1,16 & 27 & 4,0 & 22 \\
\hline P2E2C3 & 61.176 & 57.353 & 2.500 & 22,86 & 2,31 & 1,34 & 1,05 & 29 & 3,5 & 20 \\
\hline
\end{tabular}

P1: plantio direto; P2: preparo reduzido; E1: adubação de pré-semeadura; E2: adubação na semeadura; C1: DKB 333B; C2: CO 32; C3: AL Bandeirante. 
aérea restante. Assim, neste estudo, o índice de colheita maior que 1 indicou que houve maior acúmulo de matéria seca nos grãos em relação ao acúmulo das demais partes aéreas da planta. Apenas os tratamentos P2E2C1, P1E1C3 e P2E1C1 apresentaram IC menor que 1. A maior eficiência na alocação dos produtos da fotossíntese para os grãos foi observada no tratamento P1E2C2, demonstrado pelo seu maior IC. Durães et al. (2002) relatam que plantas pequenas podem resultar em IC mais altos. Portanto, possivelmente, o maior IC do P1E2C2 esteja correlacionado com sua altura de plantas e também com o diâmetro do colmo, pois nesse tratamento foram verificados os menores valores para essas características. No entanto, de acordo com Durães et al. (2002), nem sempre o maior IC está associado à maior produtividade de grãos (Quadro 4).

Na diagnose foliar, a parte amostrada deve ser representativa da planta toda e o órgão de controle mais freqüentemente escolhido é a folha, pois esta é a sede do metabolismo e reflete bem, na sua composição, as mudanças na nutrição. Os teores de $\mathrm{P}$ e $\mathrm{K}$ nas folhas de milho na época do pendoamento estão dentro dos teores considerados adequados por Raij et al. (1996), não se constatando nos tratamentos a deficiência desses nutrientes (Quadro 3). Esses autores consideram que os teores adequados de $\mathrm{N}$ em folhas de milho estão na faixa de 27 a $35 \mathrm{~g} \mathrm{~kg}^{-1}$. Assim, os tratamentos P1E2C2, P2E1C1, P2E1C2 e P2E1C3, apesar de estarem próximos desses valores, apresentaram teores de $\mathrm{N}$ nas folhas abaixo dessa faixa. Como se pode constatar, com exceção do tratamento P1E2C2, os menores teores de N nas folhas ocorreram nos tratamentos de preparo reduzido combinado com a adubação de pré-semeadura. Pode-se inferir que esses resultados sejam decorrentes da ação do escarificador, pois este promove a desagregação do solo no sentido de baixo para cima, rompendo camadas compactadas (Castro, 1989) e aumentando a macroporosidade (Tormena et al., 2002). Dessa forma, a infiltração de água pode ter ocorrido mais rapidamente no preparo reduzido em relação ao sistema plantio direto e, assim, ter ocasionado a lixiviação de uma pequena fração do $\mathrm{N}$ aplicado em pré-semeadura para maiores profundidades, diminuindo sua disponibilidade nos estádios iniciais de crescimento e desenvolvimento da cultura do milho.

O índice de espiga variou de 0,97 (P2E1C2) a 1,05 (P1E2C1, P2E2C1 e P1E1C3), indicando que as plantas dos tratamentos tiveram alta prolificidade (Quadro 4). A massa de mil grãos variou de 617 a 576, observada nos tratamentos $\mathrm{P} 1 \mathrm{E} 1 \mathrm{C} 1 \mathrm{e} \mathrm{P} 2 \mathrm{E} 2 \mathrm{C} 2$, respectivamente. Verifica-se que os menores valores de índice de espiga e massa de mil grãos foram obtidos nos tratamentos com maiores populações de plantas. Também Silva et al. (1999) e Flesh \& Vieira (2004) verificaram redução no índice de espiga e na massa de mil grãos com o aumento da população de plantas.

No sistema plantio direto com adubação de présemeadura, apenas no cultivar DKB 333B foi observada maior produtividade em relação à adubação realizada no momento da semeadura (Quadro 4), mostrando que diferentes cultivares de milho respondem de maneira diferenciada à antecipação da adubação no sistema plantio direto. Nota-se que para o cultivar CO 32 a maior produtividade foi obtida no sistema plantio direto, independentemente das épocas de adubação estudadas. Pode-se observar que a adubação de pré-semeadura diminuiu a produtividade do AL Bandeirante, demonstrando que essa variedade tem melhor desempenho com a adubação realizada junto à semeadura. Esses resultados permitem inferir que existem genótipos de milho mais bem adaptados para cada sistema de manejo do solo, para cada época de adubação, como também para a combinação desses dois fatores.

Quadro 4. Valores médios de índice de espiga (IE), comprimento (CE) e diâmetro (DE) da espiga, número de fileiras de grãos (NF) e número de grãos (NG) por espiga, massa de mil grãos (M) e produtividade de grãos

\begin{tabular}{|c|c|c|c|c|c|c|c|}
\hline Tratamento & IE & $\mathbf{C E}$ & DE & NF & NGE & M & Produtividade \\
\hline & & $\mathrm{cm}$ & $\mathrm{mm}$ & & & $\mathrm{g}$ & $\mathrm{kg} \mathrm{ha}^{-1}$ \\
\hline P1E1C1 & 1,00 & 18,03 & 46,94 & 12,90 & 471 & 617,08 & 10.967 \\
\hline $\mathrm{P} 1 \mathrm{E} 1 \mathrm{C} 2$ & 1,00 & 15,85 & 57,63 & 13,70 & 487 & 598,51 & 9.597 \\
\hline P1E1C3 & 1,05 & 16,68 & 48,23 & 14,30 & 485 & 596,89 & 8.430 \\
\hline $\mathrm{P} 1 \mathrm{E} 2 \mathrm{C} 1$ & 1,05 & 17,68 & 47,16 & 13,73 & 513 & 601,16 & 10.063 \\
\hline $\mathrm{P} 1 \mathrm{E} 2 \mathrm{C} 2$ & 0,99 & 15,50 & 46,61 & 13,90 & 458 & 591,07 & 9.742 \\
\hline $\mathrm{P} 1 \mathrm{E} 2 \mathrm{C} 3$ & 1,04 & 17,04 & 47,25 & 14,15 & 484 & 611,28 & 9.459 \\
\hline P2E1C1 & 1,03 & 17,55 & 46,70 & 13,55 & 481 & 598,10 & 10.441 \\
\hline $\mathrm{P} 2 \mathrm{E} 1 \mathrm{C} 2$ & 0,97 & 15,05 & 45,69 & 14,10 & 472 & 584,47 & 9.067 \\
\hline P2E1C3 & 1,01 & 16,91 & 49,26 & 14,61 & 482 & 607,81 & 9.138 \\
\hline $\mathrm{P} 2 \mathrm{E} 2 \mathrm{C} 1$ & 1,05 & 17,95 & 47,57 & 13,95 & 502 & 605,25 & 10.544 \\
\hline $\mathrm{P} 2 \mathrm{E} 2 \mathrm{C} 2$ & 1,00 & 16,33 & 46,58 & 13,90 & 496 & 576,39 & 9.385 \\
\hline $\mathrm{P} 2 \mathrm{E} 2 \mathrm{C} 3$ & 1,04 & 17,10 & 50,33 & 15,40 & 465 & 611,39 & 9.297 \\
\hline
\end{tabular}

P1: plantio direto; P2: preparo reduzido; E1: adubação de pré-semeadura; E2: adubação na semeadura; C1: DKB 333B; C2: CO 32; C3: AL Bandeirante. 
Também se verifica a tendência de obter maiores produtividades no preparo reduzido quando a adubação é realizada no momento da semeadura do milho, possivelmente devido à ação do escarificador, como explicado anteriormente para o teor de $\mathrm{N}$ presente no tecido foliar.

A maior produtividade foi obtida no tratamento P1E1C1, e a menor, no P1E1C3 (Quadro 4). Como pode ser observado na figura 1, a precipitação pluvial acumulada entre os períodos da adubação de présemeadura à semeadura, à adubação de cobertura e ao início do florescimento da cultura do milho foi de aproximadamente 170, 306 e $665 \mathrm{~mm}$, respectivamente, porém isso não prejudicou a produtividade média dos tratamentos em que a adubação foi antecipada, pois a produtividade não diferiu significativamente em função das épocas de adubação (Quadro 2), indicando que essa quantidade de precipitação pluvial não foi excessiva a ponto de promover grande perda do $\mathrm{N}$ aplicado em pré-semeadura para camadas mais profundas do solo por lixiviação. Esses resultados concordam com os obtidos por Basso \& Ceretta (2000), quando avaliaram a antecipação da adubação de cobertura para pré-semeadura em anos de precipitação pluvial normal, com milho cultivado em sucessão ao nabo forrageiro. Em anos com excesso de precipitação pluvial, esses autores observaram redução da produtividade quando foi realizada adubação de présemeadura. Entretanto, Wolschick et al. (2003) relataram que a produtividade não foi afetada significativamente pelas diferentes épocas de adubação, mesmo com elevadas precipitações pluviais. Já Sá (1996) observou que a aplicação de N em présemeadura foi vantajosa mesmo com precipitação pluvial de $330 \mathrm{~mm}$ entre a adubação de pré-semeadura e a semeadura do milho. É importante ressaltar que os resíduos vegetais no solo, dependendo da sua relação $\mathrm{C} / \mathrm{N}$, podem exercer influência no aproveitamento da adubação pela cultura do milho nas diferentes épocas.

Os resultados da análise de componentes principais são apresentados no quadro 5, que contém os coeficientes de correlação entre as 17 variáveis estudadas e os dois componentes principais (Y1 e Y2) calculados a partir delas. Também é apresentada a ordenação das variáveis conforme sua capacidade discriminatória. Pode-se verificar que as variáveis mais discriminatórias na formação dos grupos foram comprimento da espiga, população inicial e final de plantas e diâmetro do colmo, e as que exerceram menor influência foram diâmetro da espiga, número de grãos por espiga, número de fileiras de grãos por espiga e teor de $\mathrm{N}$ nas folhas.

$\mathrm{O}$ primeiro componente principal $(\mathrm{Y} 1)$ reteve $43,65 \%$ da informação total contida no conjunto das 17 variáveis. O segundo componente principal (Y2) reteve outros $17,44 \%$, resultando num total de $61,09 \%$.

Apesar de os sinais positivos e negativos estarem ligados à forma de calcular os vetores da matriz de covariância e, portanto, poderem ser invertidos sem prejuízo das conclusões, mantiveram-se neste estudo os sinais conforme obtidos.

PS: pré-semeadura; Se: semeadura; Co: cobertura; Flo: florescimento; C: colheita

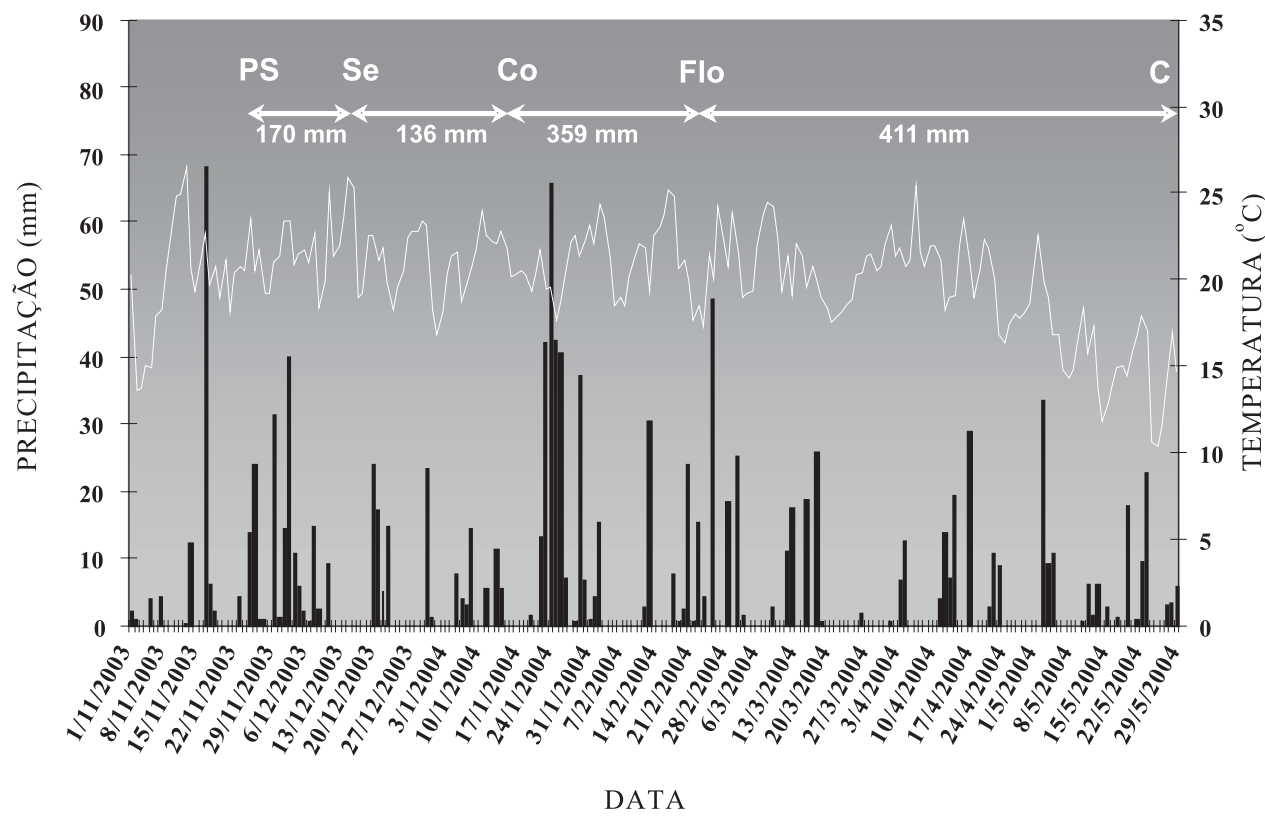

Figura 1. Temperatura média e precipitação pluvial durante o período de condução do experimento. 
Dessa forma, considerando o primeiro componente principal (Y1), as variáveis de maior contribuição, correlacionadas positivamente com ele, foram diâmetro do colmo, índice de espiga e comprimento da espiga, ao passo que as correlacionadas mais negativamente foram teor de P na folha, população final e população inicial.

Quanto ao segundo componente principal (Y2), as variáveis de maior contribuição correlacionadas positivamente foram a produtividade e o teor de $\mathrm{K}$ nas folhas, enquanto as correlacionadas mais negativamente foram número de fileiras de grãos por espiga, índice de colheita e diâmetro da espiga.

A figura 2 foi construída com os pares ordenados dos componentes principais Y1 e Y2. Na representação gráfica sobre o plano cartesiano, observa-se uma nítida distribuição dos 12 tratamentos, formando três grupos distintos.

Quadro 5. Correlações entre as variáveis originais e os dois primeiros componentes principais (Y1 e Y2); percentagem de informação contida nas 17 variáveis e retida em cada componente principal; e ordenação das variáveis de acordo com sua capacidade discriminatória (CD)

\begin{tabular}{|c|c|c|c|}
\hline Característica avaliada & Y1 & Y2 & CD \\
\hline População inicial & $-0,248072$ & 0,372114 & 3 \\
\hline População final & $-0,266409$ & 0,330376 & 2 \\
\hline $\mathrm{N}^{\mathrm{o}}$. de plantas quebradas & $-0,240189$ & $-0,145191$ & 9 \\
\hline Diâmetro do colmo & 0,322625 & 0,180503 & 4 \\
\hline Altura de plantas & 0,284562 & 0,075246 & 8 \\
\hline Altura da espiga & 0,281712 & 0,010585 & 13 \\
\hline Índice de colheita & $-0,179966$ & $-0,285448$ & 11 \\
\hline Teor de nitrogênio nas folhas & 0,238758 & $-0,102530$ & 14 \\
\hline Teor de fósforo nas folhas & $-0,284826$ & 0,087813 & 7 \\
\hline Teor de potássio nas folhas & $-0,162604$ & 0,417135 & 6 \\
\hline Índice de espiga & 0,326398 & $-0,122448$ & 5 \\
\hline Comprimento da espiga & 0,335068 & 0,180126 & 1 \\
\hline Diâmetro da espiga & $-0,025943$ & $-0,153842$ & 17 \\
\hline $\mathrm{N}^{\circ}$. de fileiras de grãos por espiga & $-0,136259$ & $-0,343569$ & 15 \\
\hline $\mathrm{N}^{\circ}$. de grãos por espiga & 0,166633 & 0,148684 & 16 \\
\hline Massa de mil grãos & 0,263078 & $-0,073305$ & 12 \\
\hline Produtividade & 0,115718 & 0,450128 & 10 \\
\hline \% Informação total & 43,65 & 17,44 & \\
\hline \% Informação acumulada & 43,65 & 61,09 & \\
\hline
\end{tabular}

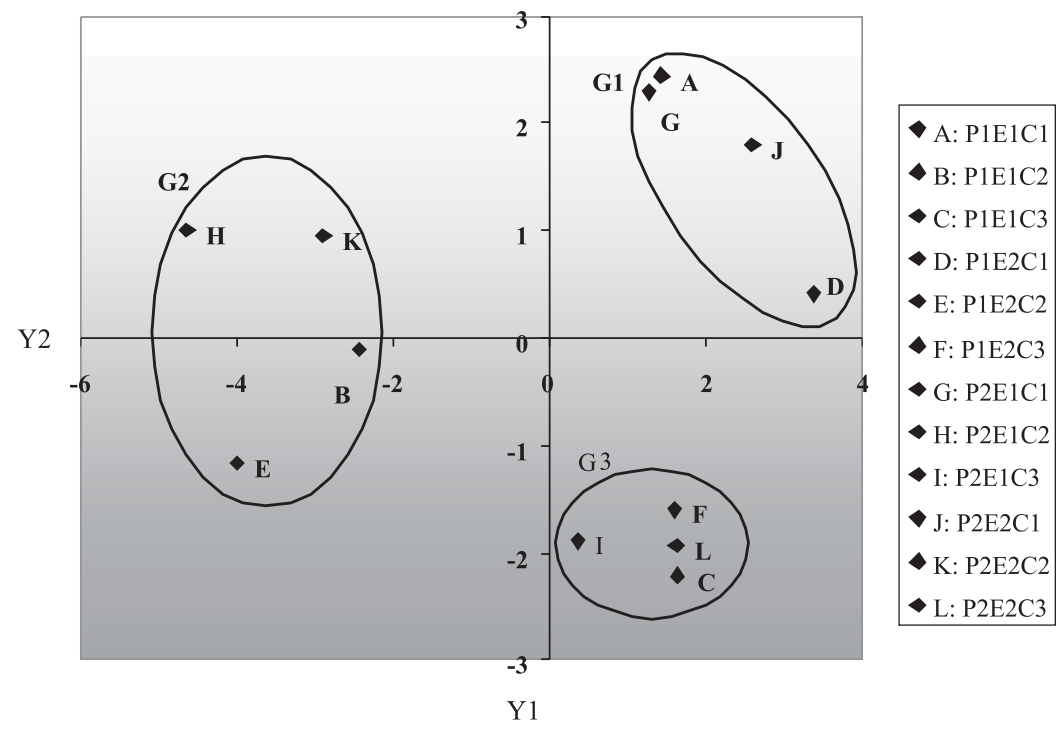

Figura 2. Ordenação dos 12 tratamentos utilizando-se os pares de valores dos componentes principais Y1 e Y2, obtidos na análise de componentes principais, com indicação dos grupos formados (G1, G2 e G3) onde, na legenda, $\mathrm{P} 1$ = plantio direto, $\mathrm{P2}=$ preparo reduzido, $\mathrm{E} 1$ = adubação na pré-semeadura, $\mathrm{E} 2$ = adubação na semeadura, C1 = DKB 333B, C2 = CO 32 e C3 = AL Bandeirante. 
O primeiro grupo é formado pelas letras A, G, J e D; o segundo, pelas letras H, K, E e B; e o terceiro, pelas letras I, F, L e C. Portanto, pode-se constatar que tanto os sistemas de manejo do solo quanto as épocas de adubação exerceram pouca ou nenhuma influência na formação dos grupos, ou seja, as variações ocorridas para cada componente de produção da cultura do milho são oriundas, principalmente, das diferenças genéticas entre os três cultivares de milho. Nos quadros 6 e 7 são apresentados os desempenhos dos grupos para cada uma das características avaliadas.

O grupo 1, formado pelo cultivar DKB 333B, apresentou maiores valores para diâmetro do colmo, altura de planta, altura de inserção da primeira espiga, teor de $\mathrm{N}$ nas folhas, comprimento da espiga, número de grãos por espiga e produtividade. O grupo 2, formado pelo cultivar CO 32 , mostrou maiores valores para população inicial, população final, número de plantas quebradas, índice de colheita, teor de $\mathrm{P}$ e K nas folhas e diâmetro da espiga. O grupo 3, formado pela variedade AL Bandeirante, apresentou os maiores valores para teor de $\mathrm{N}$ nas folhas, índice de espiga, número de fileiras de grãos por espiga e massa de mil grãos.

No dendrograma obtido da análise de agrupamento, o eixo vertical representa a distância euclidiana simples, e o eixo horizontal, os tratamentos (Figura 3). O dendrograma apresenta os pontos de fusão dos grupos formados em cada estádio, onde existem tantos grupos quanto o número de tratamentos, ou seja, cada tratamento forma um agrupamento. Inicialmente, os tratamentos mais similares são agrupados e fundidos formando um único grupo. Eventualmente, o processo é repetido, e, com o decréscimo da similaridade, todos os subgrupos são fundidos formando um único grupo com todos os tratamentos. Assim, considerando todas as características agronômicas avaliadas, pode-se observar que a variedade utilizada apresentou desempenho mais próximo daquele do híbrido simples do que do híbrido triplo, pois no nível de homogeneidade de 1,0, na distância euclidiana, podese verificar a formação de dois grupos distintos: o primeiro, constituído pelos cultivares DKB 333B e AL Bandeirante, e o segundo, pelo cultivar CO 32.

Se for traçada uma linha de corte horizontal no nível de homogeneidade de 0,86 , verifica-se a formação de quatro grupos homogêneos e distintos entre si, sendo o primeiro grupo formado pelas letras $\mathrm{G}, \mathrm{J}, \mathrm{A}$ e D; o segundo, pelas letras F, I, L e C; o terceiro, pelas letras H, K e E; e o quarto, pela letra B (Figura 3). Portanto, também na análise de agrupamento pode-se observar que os grupos foram formados, principalmente, a partir da diferença genética entre os cultivares de milho, confirmando os resultados obtidos na análise de variância.

Como se pode notar, a avaliação conjunta do dendrograma resultante da análise multivariada e do gráfico bidimensional obtido com os dois primeiros componente principais possibilitou inferir com maior

Quadro 6. Valores médios de população inicial (PI), população final (PF), número de plantas quebradas (PQ), diâmetro do colmo (DC), altura de plantas (AP), altura de inserção da primeira espiga (AE), índice de colheita (IC), teor de nitrogênio $(\mathrm{N})$, fósforo $(\mathrm{P})$ e potássio $(\mathrm{K})$ nas folhas dos grupos formados pela análise de componentes principais

\begin{tabular}{|c|c|c|c|c|c|c|c|c|c|c|}
\hline Grupo & PI & PF & $\mathbf{P Q}$ & DC & $\mathbf{A P}$ & $\mathbf{A E}$ & IC & $\mathbf{N}$ & $\mathbf{P}$ & $\mathbf{K}$ \\
\hline & 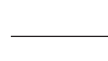 & plantas ha ${ }^{-1}$ & - & $\mathrm{mm}$ & $\longrightarrow$ & $\longrightarrow$ & & 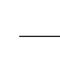 & $\mathrm{g} \mathrm{kg}^{-1}$ & - \\
\hline 1 & 65.368 & 62.868 & 694 & 23,44 & 2,25 & 1,27 & 1,01 & 28 & 3,08 & 22 \\
\hline 2 & 67.868 & 66.912 & 2.014 & 20,65 & 2,04 & 1,12 & 1,18 & 26 & 3,70 & 23 \\
\hline 3 & 61.176 & 58.088 & 1.458 & 22,19 & 2,21 & 1,26 & 1,14 & 28 & 3,16 & 19 \\
\hline
\end{tabular}

Quadro 7. Valores médios de índice (IE), comprimento (CE) e diâmetro (DE) da espiga, número de fileiras de grãos (NF) e número de grãos por espiga (NGE), massa de mil grãos (M) e produtividade (P) dos grupos formados pela análise de componentes principais

\begin{tabular}{|c|c|c|c|c|c|c|c|}
\hline Grupo & IE & CE & DE & NF & NGE & $\mathbf{M}$ & $\mathbf{P}$ \\
\hline & & $\mathrm{cm}$ & $\mathrm{mm}$ & & & g & $\mathrm{kg} \mathrm{ha}^{-1}$ \\
\hline 1 & 1,03 & 17,80 & 47,09 & 13,53 & 491,88 & 605,39 & 10.504 \\
\hline 2 & 0,99 & 15,68 & 49,13 & 13,90 & 478,08 & 587,61 & 9.448 \\
\hline 3 & 1,04 & 16,93 & 48,77 & 14,61 & 478,77 & 606,84 & 9.081 \\
\hline
\end{tabular}




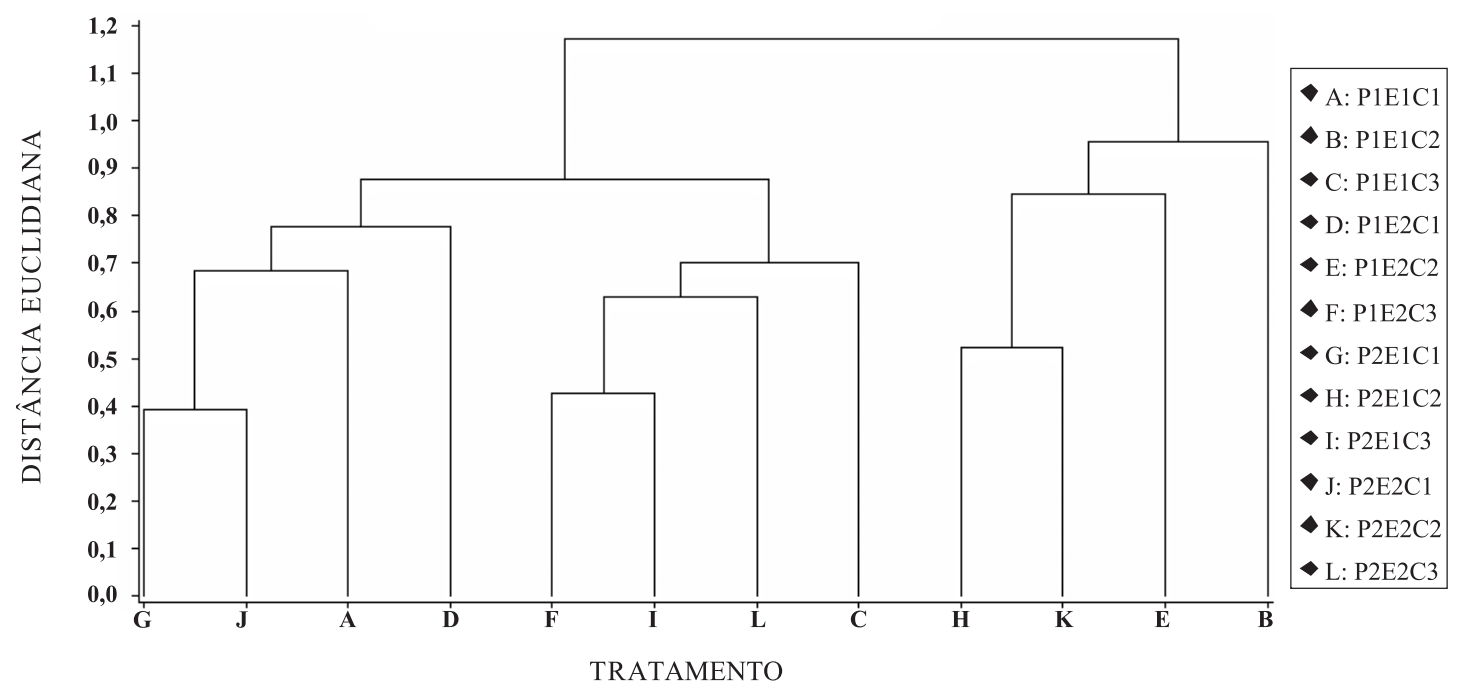

Figura 3. Dendrograma resultante da análise de agrupamento dos 12 tratamentos, utilizando-se a distância euclidiana média como coeficiente de similaridade e o algoritmo UPGMA. P1 = plantio direto; P2 = preparo reduzido; $\mathrm{E} 1$ = adubação na pré-semeadura; $\mathrm{E} 2$ = adubação na semeadura; $\mathrm{C} 1=\mathrm{DKB} 333 \mathrm{~B}$; $\mathrm{C} 2=$ CO 32; C3 = AL Bandeirante.

segurança os grupos ou os tratamentos similares, suas características e quais variáveis mais contribuíram para o processo de agrupamento dos tratamentos. Dessa forma, é possível definir as combinações entre sistemas de manejo do solo, épocas de adubação e cultivares que proporcionarão resultados semelhantes referentes às características avaliadas e ao desempenho da cultura do milho.

\section{CONCLUSÕES}

1. A antecipação da adubação de semeadura em 22 dias não diferiu da adubação realizada no momento da semeadura, em relação ao desempenho da cultura do milho.

2. Cada cultivar de milho responde de maneira diferenciada à antecipação da adubação no sistema plantio direto.

3. No preparo reduzido ocorre a tendência de a maior produtividade ser obtida quando a adubação é realizada no momento da semeadura do milho.

4. As diferenças observadas no desempenho da cultura do milho devem-se principalmente à divergência genética entre os cultivares.

5. A concordância entre os resultados da análise de agrupamentos e da análise de componentes principais com a análise de variância evidencia a adequação das técnicas estatísticas multivariadas utilizadas neste trabalho.

6. O uso combinado das técnicas multivariadas possibilitou inferir com maior segurança os agrupamentos formados e suas características.

\section{LITERATURA CITADA}

BASSO, C.J. \& CERETTA, C.A. Manejo do nitrogênio no milho em sucessão a plantas de cobertura de solo, sob plantio direto. R. Bras. Ci. Solo, 24:905-915, 2000.

CARVALHO, W.A.; ESPÍNDOLA, C.R. \& PACCOLA, A.A. Levantamento de solos da Fazenda Lageado - Estação Experimental "Presidente Médici". Botucatu, Universidade Estadual de São Paulo, 1983. 95p. (Boletim Científico, 1)

CANTARELLA, H. \& DUARTE, A.P. Manejo da fertilidade do solo para a cultura do milho. In: GALVÃO, J.C.C. \& MIRANDA, G.V., eds. Tecnologia de produção de milho. Viçosa, MG, Universidade Federal de Viçosa, 2004. p.139182.

CASTRO, O.M. Preparo do solo para a cultura do milho. Campinas, Fundação Cargill, 1989. 41p.

CERETTA, C.A. Adubação nitrogenada no sistema plantio direto: Sucessão aveia/milho. In: CONFERÊNCIA ANUAL DE PLANTIO DIRETO, 2., Ijuí, 1998. Anais. Passo Fundo, Aldeia Norte, 1998. p.49-62.

COELHO, A.M.; CRUZ, J.C. \& PEREIRA FILHO, I.A. Rendimento de milho no Brasil: Chegamos ao máximo. In: SIMPÓSIO DE ROTAÇ̃̃O SOJA/MILHO NO PLANTIO DIRETO, 3., Piracicaba, 2002. Anais. Piracicaba, Escola Superior de Agricultura Luiz de Queiroz, 2002. CD-ROM.

CUNHA, A.R. \& MARTINS, D. Classificação climática para os municípios de Botucatu e São Manuel, SP. Irriga, 2009. No prelo.

DICK, W.A.; MCCOY, E.L.; EDWARDS, W.M. \& LAL, R. Continuous application of no-tillage to Ohio soils. Agron. J., 83:65-73, 1991. 
DURÃES, F.O.M.; MAGALHÃES, P.C. \& OLIVEIRA, A.C. Índice de colheita genético e as possibilidades da genética fisiológica para melhoramento do rendimento de milho. R. Bras. Milho e Sorgo, 1:33-40, 2002.

EMPRESA BRASILEIRA DE PESQUISA AGROPECUÁRIA EMBRAPA. Centro Nacional de Pesquisa de Solos. Sistema brasileiro de classificação de solos. Rio de Janeiro, 1999. $412 \mathrm{p}$

FOOD AND AGRICULTURE ORGANIZATION OF THE UNITED NATIONS - FAO. Soil map of the world. Paris, FAO/Unesco, 1974. 59p.

FLESCH, R.D. \& VIEIRA, L.C. Espaçamentos e densidades de milho com diferentes ciclos no oeste de Santa Catarina, Brasil. Ci. Rural, 34:25-31, 2004.

GROSS, M.R.; PINHO, R.G.V. \& BRITO, A.H. Adubação nitrogenada, densidade de semeadura e espaçamento entre fileiras na cultura do milho em sistema plantio direto. Ci. Agrotec., 30:387-393, 2006.

MAI, M.E.M.; CERETTA, C.A.; BASSO, C.J.; SILVEIRA, M.J.; PAVINATO, A. \& PAVINATO, P.S. Manejo da adubação nitrogenada na sucessão aveia-preta/milho no sistema plantio direto. Pesq. Agropec. Bras., 38:125-131, 2003.

MIRANDA, G.V.; COIMBRA, R.R.; GODOY, C.L.; SOUZA, L.V.; GUIMARÃES, L.J.M. \& MELO, A.V. Potencial de melhoramento e divergência genética de cultivares de milho-pipoca. Pesq. Agropec. Bras., 38:681-688, 2003.

MOLL, R.H.; KAMPRATH, E.J. \& JACKSON, W.A. Analysis and interpretation of factors which contribute to efficiency of nitrogen utilization. Agron. J., 74:562-564, 1982.

MOODY, J.E.; SHER, G.M. \& JONES Jr., J.N. Growing corn without tillage. Soil Sci. Soc. Am. J., 6:516-517, 1961.

PEREIRA FILHO, I.A.; PACHECO, C.A.P.; CRUZ, J.C.; KARAM, D. \& GUISCEM, J. Produtividade e algumas características do milho pipoca BRS Ângela, semeada em diferentes espaçamentos e densidades de semeaduras. In: CONGRESSO NACIONAL DE MILHO E SORGO, 24., Florianópolis, 2002. Resumos. Florianópolis, Associação Brasileira de Milho e Sorgo, 2002. CD-ROM.
PÖTTKER, D. \& WIETHÖLTER, S. Antecipação da aplicação de nitrogênio em milho. In: EMBRAPA TRIGO: Pesquisa em Andamento, n.1, 1999. Disponível em: <http:// www.cnpt.embrapa.br/biblio/p_pa01.htm.>. Acesso em: 29 ago. de 2003.

RAIJ, B.van; CANTARELLA, H.; QUAGGIO, J.A. \& FURLANI, A.M.C. Recomendação de adubação e calagem para o Estado de São Paulo. 2.ed. Campinas, Instituto Agronômico \& Fundação IAC, 1996. 285p. (Boletim Técnico, 100)

ROSOLEM, C.A.; GARCIA, R.A.; FOLONI, J.S.S. \& CALONEGO, J.C. Lixiviação de potássio no solo de acordo com suas doses aplicadas sobre palha de milheto. R. Bras. Ci. Solo, 30:813-819, 2206.

SÁ, J.C.M. Manejo de nitrogênio na cultura de milho no sistema plantio direto. Passo Fundo, Aldeia Norte, 1996. 23p.

SILVA, E.C.; MURAOKA, T.; BUZETTI, S. \& TRIVELIN, P.C.O. Manejo de nitrogênio no milho sob plantio direto com diferentes plantas de cobertura, em Latossolo Vermelho. Pesq. Agropec. Bras. 41:477-486, 2006.

SILVA, P.R.F.; ARGENTA, G. \& REZERA, F. Resposta de híbridos de milho irrigado à densidade de plantas em três épocas de semeadura. Pesq. Agropec. Bras., 34:585-592, 1999.

TOKURA, A.M.; FURTINI NETO, A.E.; CURI, N.; FAQUIN, V.; KURIHARA, C.H. \& ALOVISI, A.A. Formas de fósforo em solo sob plantio direto em razão da profundidade e tempo de cultivo. Pesq. Agropec. Bras., 37:1467-1476, 2002.

TORMENA, C.A.; BARBOSA, M.C.; COSTA, A.C.S. \& GONÇALVES, C.A. Densidade, porosidade e resistência à penetração em Latossolo cultivado sob diferentes sistemas de preparo do solo. Sci. Agric., 59:795-801, 2002.

WOLSCHICK, D.; CARLESSO, R.; PETRY, M.T. \& JADOSKI, S.O. Adubação nitrogenada na cultura do milho no sistema plantio direto em ano com precipitação pluvial normal e com "El Niño". R. Bras. Ci. Solo, 27:461-468, 2003. 